\title{
Bridging the gap between cellulose chemistry and heterogeneous catalysis
}

\author{
S. Van de Vyver ${ }^{1}$, J. Geboers ${ }^{1}$, L. Peng ${ }^{1}$, F. de Clippel $^{1}$, \\ M. Dusselier ${ }^{1}$, T. Vosch $^{2}$, L. Zhang ${ }^{3}$, G. Van Tendeloo ${ }^{3}$, \\ C. J. Gommes ${ }^{4,5}$, B. Goderis ${ }^{5}$, P. A. Jacobs ${ }^{1}$ \& B. F. Sels ${ }^{1}$ \\ ${ }^{1}$ Center for Surface Chemistry and Catalysis, \\ Katholieke Universiteit Leuven, Belgium \\ ${ }^{2}$ Department of Chemistry, Katholieke Universiteit Leuven, Belgium \\ ${ }^{3}$ Center for Electron Microscopy for Materials Science, \\ University of Antwerp, Belgium \\ ${ }^{4}$ Department of Chemical Engineering, University of Liège, Belgium \\ ${ }^{5}$ Department of Molecular and Nanomaterials, \\ Katholieke Universiteit Leuven, Belgium
}

\begin{abstract}
Although cellulosic biomass offers a promising alternative as an abundant renewable resource in the production of biofuels and platform chemicals, so far only a few studies have reported its aqueous-phase conversion into glucose or sugar alcohols using solid chemocatalysts. The principal reason is that these polymeric biomolecules with semi-crystalline structure cannot penetrate the pores of conventional heterogeneous chemocatalysts. New advances in the conversion of cellulose thus require the design of efficient multifunctional catalytic systems with sterically accessible acid and metal sites.
\end{abstract}

Keywords: biomass, carbon nanofibers, cellulose, glucose, heterogeneous catalysis, hydrogenation, hydrolysis, nanocomposites, nickel, sugar alcohols.

\section{Introduction}

Environmental concerns about the depletion of fossil fuel reserves, the impact of anthropogenic $\mathrm{CO}_{2}$ emissions and increasing energy demands have encouraged the exploration of new catalytic methods for converting cellulose into valuable 
platform chemicals and biofuels $[1,2]$. The development of these sustainable catalytic transformations could potentially provide a long-term solution to the industrial dependence on fossil carbon, requiring in 2025 production of up to $30 \%$ of raw materials for the chemical industry from renewable resources $[3,4]$. With an abundance of approximately 720 billion tonnes, i.e. $40 \%$ of the annual net yield of photosynthesis, cellulose is the world's largest organic raw material resource [5]. The blueprints of the "new" sustainable cellulose chemistry are based on some key elements, namely controlled depolymerization and catalytic cascade reactions (e.g., hydrogenation, hydrogenolysis), which, when put together, yield a pool of molecules that can be used for synthesis of industrial intermediates and fine chemicals. Van de Vyver et al. [1] recently reviewed new advances in the conversion of cellulose, requiring the design of multifunctional catalysts with sterically accessible acid and metal sites. Our work provides an example for how two solid catalytic systems can be used for: (i) the hydrolysis of cellulose to glucose and (ii) the hydrolytic hydrogenation of cellulose to sugar alcohols such as sorbitol and mannitol. Before the two catalytic strategies are discussed, characterization of the substrate as well as a mechanical pretreatment method to decrease cellulose crystallinity will be addressed.

\subsection{Pretreatment and characterization of cellulose}

The potential of mechanical disruption of cellulose by breaking hydrogen bonds, taking into account integration with hydrolytic catalytic processes, is now being thoroughly studied by our research group [6-9]. In the present study, cellulose (Avicel PH-101, microcrystalline) was characterized (i) as received and (ii) after $24 \mathrm{~h}$ ball-milling pretreatment. Ball-milling with $25 \mathrm{~g}$ of cellulose powder was carried out using zirconia balls (mass $7.5 \mathrm{~g}$; diameter $1.8 \mathrm{~cm}$ ). The micrographs in Figure 1, taken with a high resolution scanning electron microscope (SEM; Philips XL-30 FEG), provide clear information about cellulose particle size distributions before and after ball-milling.

$\mathrm{X}$-ray diffraction $(\mathrm{XRD})$ patterns of the $\mathrm{Ni} / \mathrm{CNF}$ catalyst were recorded at room temperature with a STOE STADI P Combi diffractometer. The diffracted intensity of $\mathrm{CuK} \alpha$ radiation (wavelength of $0.154 \mathrm{~nm}$ ) was measured in a $2 \theta$
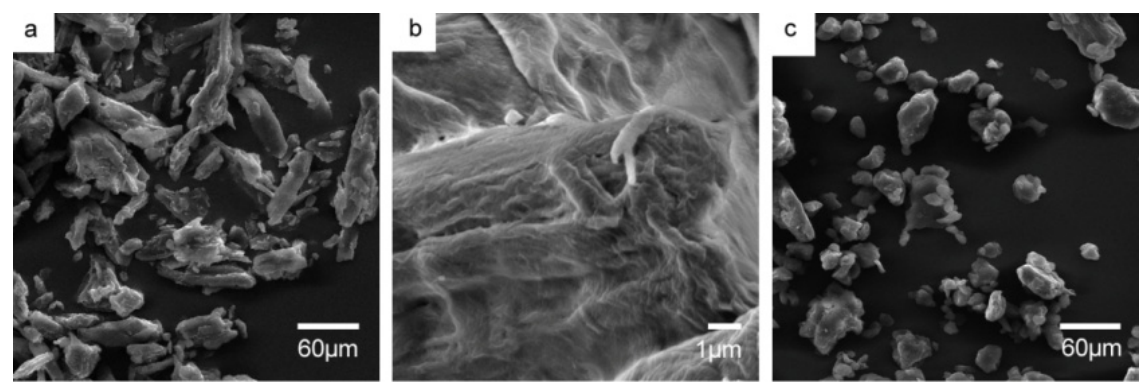

Figure 1: $\quad$ SEM images of Avicel cellulose, before (average particle size $50 \mu \mathrm{m} ; \mathrm{a}, \mathrm{b}$ ) and after ball-milling (average particle size $20 \mu \mathrm{m}$; c). 
range between 5 and $75^{\circ}$. Figure 2 displays XRD patterns taken of cellulose samples unmilled and ball-milled for $24 \mathrm{~h}$. In the untreated cellulose, the major peak at $2 \theta=22.5^{\circ}$ can be assigned to the crystalline plane 002 . A comparison of the patterns clearly reveals a decrease in crystallinity of the cellulose feedstock after $24 \mathrm{~h}$ ball-milling pretreatment.

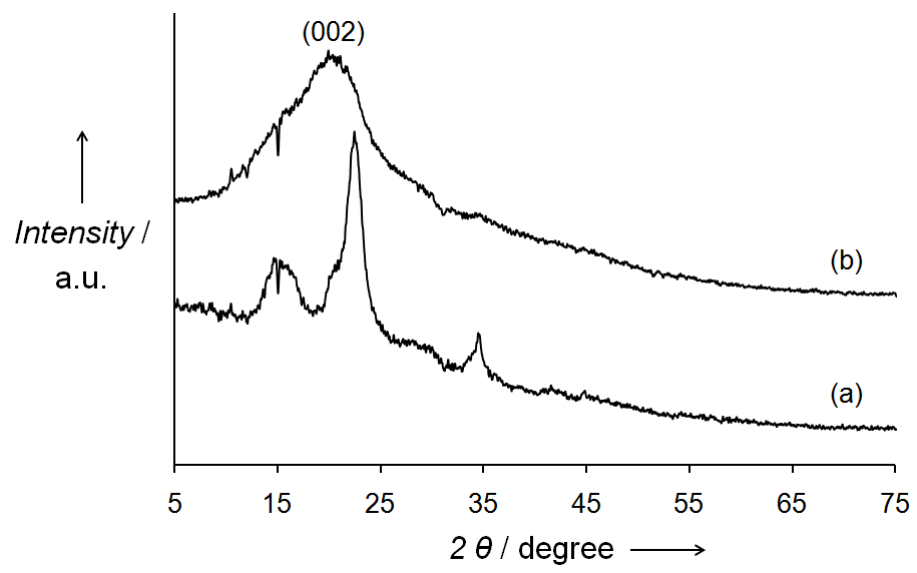

Figure 2: $\quad$ XRD patterns of cellulose before (a) and after ball-milling (b).

The ${ }^{13} \mathrm{C}$ CP MAS NMR spectra of cellulose with and without ball-milling were recorded on a Bruker Avance DSX400 spectrometer (9.4 T). The decreasing peak ratios of $\left.\mathrm{C}_{(86-92} \mathrm{ppm}\right) / \mathrm{C} 4_{(79-86 \mathrm{ppm})}$ and $\mathrm{C6}_{(63-67 \mathrm{ppm})} / \mathrm{C}_{(56-63 \mathrm{ppm})}$ in Figure 3 are in good agreement with the observations by Zhao et al. [10]. This, in interplay with the above XRD data, strongly suggests that more disordered cellulose is produced after ball-milling. Line widths are larger in the amorphous sample which is due to the large distribution of molecular orientations.

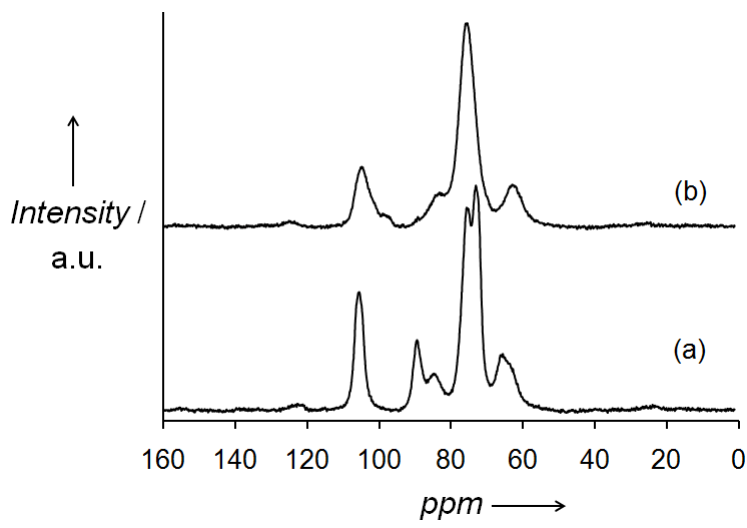

Figure 3: $\quad{ }^{13} \mathrm{C} \mathrm{CP}$ MAS NMR of cellulose before (a) and after ball-milling (b). 
IR spectra were recorded under vacuum from $\mathrm{KBr}$ pellets on a Bruker IFS 66v/S instrument. The spectra in Figure 4 also show the changes in the cellulose structure after ball-milling. The less pronounced band at $1430 \mathrm{~cm}^{-1}$ is another strong indication of a less ordered cellulose sample, since it is assigned to the $\mathrm{CH}_{2}$ scissoring motion in the cellulose I crystal. The ball-milling allows the regular arrangement of the $\mathrm{CH}_{2} \mathrm{OH}$ group on $\mathrm{C}_{6}$ to relax into a more random one, resulting in a broader band at $1430 \mathrm{~cm}^{-1}$.

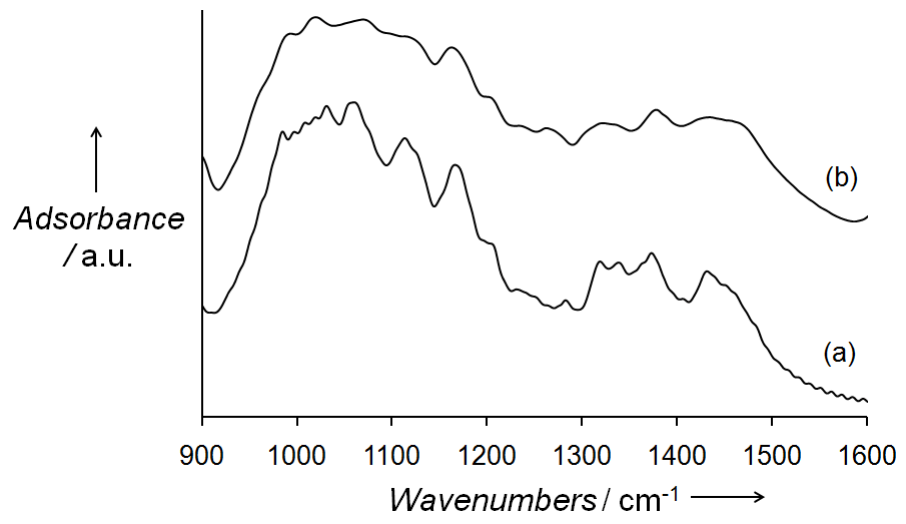

Figure 4: $\quad$ IR spectra of cellulose before (a) and after ball-milling (b).

\subsection{Hydrolysis of cellulose to glucose}

An excellent review on cellulose hydrolysis as entry point into biorefinery schemes has been published by Rinaldi and Schüth [11]. In the search for an alternative solid catalyst for cellulose hydrolysis, Van de Vyver et al. [6] recently reported the use of a new class of sulfonated silica/carbon nanocomposites, capable of achieving high glucose yields compared to reference ion-exchange resins (Amberlyst ${ }^{\circledR}$ 15, Nafion ${ }^{(B)}$ NR50) and commercial zeolites.

\subsection{Catalyst synthesis}

The hybrid materials were synthesized by the evaporation-induced triconstituent co-assembly method, wherein sucrose is used as an alternative carbon precursor, prehydrolyzed tetraethyl orthosilicate (TEOS) as silica precursor, and Pluronic F127 triblock copolymer $\left(\mathrm{EO}_{106} \mathrm{PO}_{70} \mathrm{EO}_{106}, M_{\mathrm{w}}=12600\right) \mathrm{F} 127$ as structuredirecting amphiphilic surfactant (Figure 5). In a typical preparation procedure, $6.4 \mathrm{~g}$ block copolymer F127 was dissolved in $32 \mathrm{~g}$ ethanol with $0.3 \mathrm{~g}$ concentrated $\mathrm{HCl}(37 \%)$ and the mixture was treated in an ultrasonic bath for $1 \mathrm{~h}$ to afford a clear solution. Next, $8.32 \mathrm{~g}$ TEOS and $10 \mathrm{~g}$ sucrose solution with different concentration were added in sequence. It took $20 \mathrm{~h}$ at $313 \mathrm{~K}$ to evaporate ethanol and $24 \mathrm{~h}$ at $433 \mathrm{~K}$ to thermopolymerize. Carbonization was done at $673 \mathrm{~K}$ or $823 \mathrm{~K}$ for $15 \mathrm{~h}$ under $\mathrm{N}_{2}$ flow. 

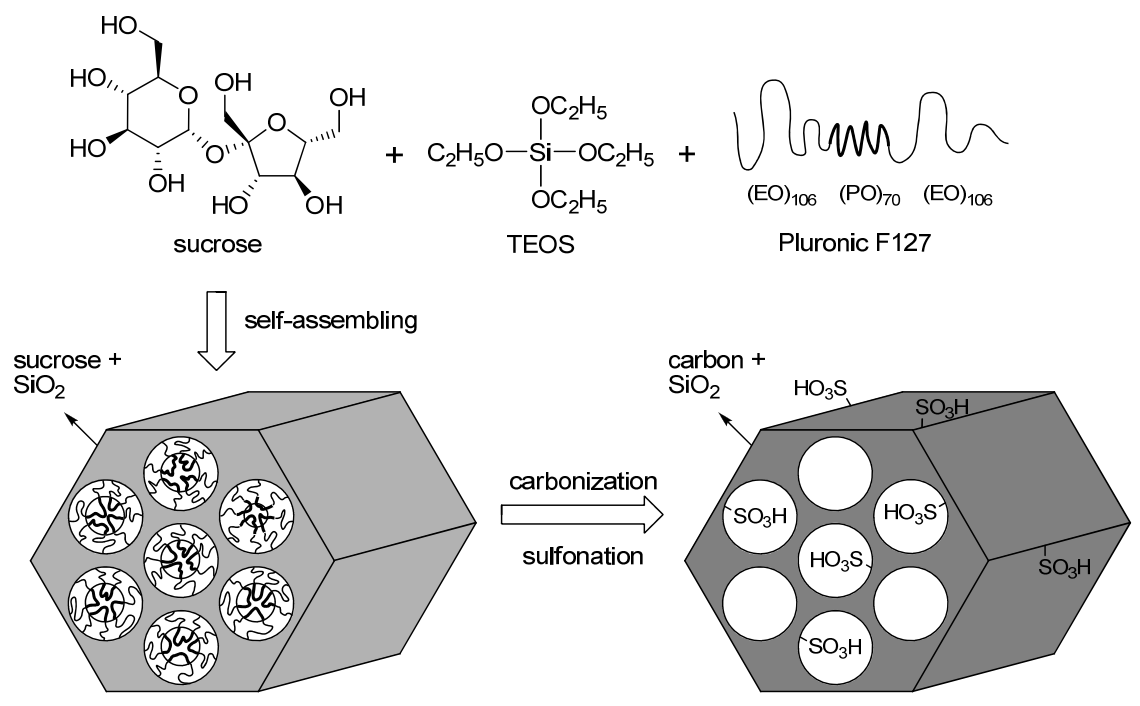

Figure 5: Schematic illustration of the proposed mechanism for formation of sulfonated silica/carbon nanocomposites (TEOS = tetraethylorthosilicate).

Three samples with different carbon content of $66 \mathrm{wt} \%$, 50wt $\%$ and $33 \mathrm{wt} \%$ were synthesized by changing the concentration of the sucrose solution added. These materials were treated with concentrated sulfuric acid $(1 \mathrm{~g}$ of solid $/ 20 \mathrm{ml}$ of $\mathrm{H}_{2} \mathrm{SO}_{4}$ ) at $423 \mathrm{~K}$ for $15 \mathrm{~h}$ in a Teflon-lined autoclave. The resulting materials were washed with hot distilled water until no sulfate ions were detected in the wash water. The as-prepared sulfonic acid functionalized silica/carbon nanocomposites are further denoted as $\mathrm{SimCn}-\mathrm{T}-\mathrm{SO}_{3} \mathrm{H}(\mathrm{m}, \mathrm{n}$ are the weight percentages of silica and carbon, respectively, and $\mathrm{T}$ is the carbonization temperature expressed in Kelvin).

\subsection{Catalyst characterization}

The Small-Angle X-ray Scattering (SAXS) patterns of the as-synthesized and sulfonated samples were measured at the Dutch-Belgian beamline (BM26) of the European Synchrotron Radiation Facility and a custom software was used to reduce the measured 2D data into 1D scattering patterns [12]. Average distances between neighbouring pores were calculated as $a=4 \pi /\left(\sqrt{3} q^{*}\right)$, where $q^{*}$ is the scattering vector of the first peak. The SAXS patterns of all samples in Figure 6 exhibit a clear maximum at scattering vector $q^{*}$, and $\operatorname{dim}$ secondary maxima are observed for some samples at larger $q$ values. Although the exact positions of the latter cannot be determined accurately, they overlap nicely those expected for cylindrical pores being stacked according to a hexagonal ( $p 6 \mathrm{~mm}$ ) symmetry, namely $q^{*}$ and $2 q^{*}$. 


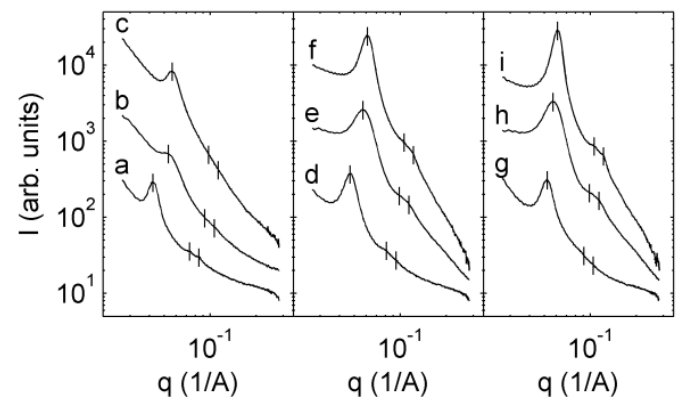

Figure 6: $\quad$ SAXS patterns of samples (a) Si33C66; (b) Si33C66-673- $\mathrm{SO}_{3} \mathrm{H}$; (c) $\mathrm{Si} 33 \mathrm{C} 66-823-\mathrm{SO}_{3} \mathrm{H}$; (d) $\mathrm{Si} 50 \mathrm{C} 50$; (e) $\mathrm{Si} 50 \mathrm{C} 50-673-\mathrm{SO}_{3} \mathrm{H}$;

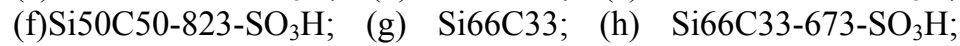
(i) $\mathrm{Si6} 6 \mathrm{C} 33-823-\mathrm{SO}_{3} \mathrm{H}$. The vertical lines indicate positions of the $(1,0),(1,1)$ and $(2,0)$ scattering peaks of a system having hexagonal symmetry [6].

The carbon content in the sulfonated silica/carbon nanocomposites was measured by thermogravimetric analysis (TGA) in $\mathrm{O}_{2}$, as shown in Figure 7. TGA was performed on a TGA Q500 (TA Instruments, Brussels, Belgium). The samples were heated from room temperature to $1073 \mathrm{~K}$ at $5 \mathrm{~K} \mathrm{~min}^{-1}$. For the sulfonic acid group-functionalized carbon-silica composite, the weight loss below $373 \mathrm{~K}$ and in range of $373-873 \mathrm{~K}$ in $\mathrm{O}_{2}$ can be attributed to the absorbed water and carbon compound, respectively, while the weight residue belongs to the silica.
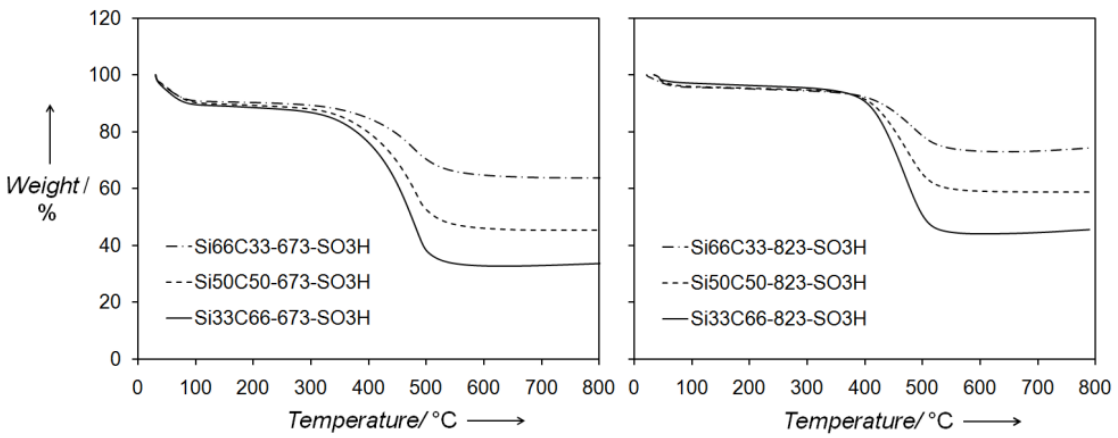

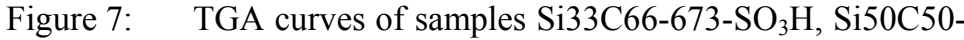
673- $\mathrm{SO}_{3} \mathrm{H}, \mathrm{Si} 66 \mathrm{C} 33-673-\mathrm{SO}_{3} \mathrm{H}, \quad \mathrm{Si} 33 \mathrm{C} 66-823-\mathrm{SO}_{3} \mathrm{H}$, $\mathrm{Si} 50 \mathrm{C} 50-{ }_{8} 23-\mathrm{SO}_{3} \mathrm{H}$ and $\mathrm{Si}_{6} 6 \mathrm{C}_{3} 3-823-\mathrm{SO}_{3} \mathrm{H}$.

\subsection{Results and discussion}

According to reference [6], Table $1 \mathrm{show}_{\mathrm{s}}$ the acid density, glucose formation rate and turnover frequency (TOF) at acid sites for $\mathrm{SimCn}-\mathrm{T}-\mathrm{SO}_{3} \mathrm{H}$. The 
expectations based on titration results are in general agreement with the catalytic observations in that glucose formation is found to occur faster on nanocomposites with higher acid density.

More interestingly, the TOF data point to the prominent role that the hybridstructured surface character plays in the hydrolytic activity of the Brønsted acid sites. Indeed, higher TOFs were determined for samples with increased $\mathrm{Si} / \mathrm{C}$ mass ratio, and hence higher hydrophilicity. In previous studies it has been found that efficient conversion of cellulose requires a good interaction between the solid acid catalyst and $\beta-1,4$ glucan [1]. In the present case, the correlation between catalyst composition and TOF data strongly suggests that the hydrophilic silica groups facilitate substrate adsorption.

Table 1: Catalytic conversion of cellulose over sulfonated silica /carbonnanocomposites. Reaction conditions: cellulose pretreated by ball-milling $0.05 \mathrm{~g}$, catalyst $0.05 \mathrm{~g}$, water $5 \mathrm{~mL}$, reaction time $24 \mathrm{~h}$, temperature $423 \mathrm{~K}$ [6].

\begin{tabular}{|c|c|c|c|c|}
\hline \multirow[t]{2}{*}{ Catalyst } & \multirow[b]{2}{*}{$\begin{array}{l}\text { Acid density } \\
\left(\mathrm{mmol} \mathrm{g}^{-1}\right)\end{array}$} & \multirow{2}{*}{$\begin{array}{l}\text { TOF } \\
\left(\mathrm{h}^{-1}\right)\end{array}$} & \multirow[b]{2}{*}{$\begin{array}{c}\text { Conv. } \\
(\%)\end{array}$} & \multirow[b]{2}{*}{$\begin{array}{l}\text { Glucose } \\
\text { yield (\%) }\end{array}$} \\
\hline & & & & \\
\hline $\mathrm{Si} 33 \mathrm{C}$ & 057 & 015 & 425 & 383 \\
\hline $\mathrm{Si} 50 \mathrm{C} 50-673-\mathrm{SO}_{3} \mathrm{H}$ & 0.40 & 0.15 & 330 & 270 \\
\hline 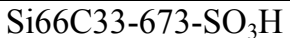 & 0.31 & 0.19 & 31.3 & 26.9 \\
\hline $\mathrm{Si} 33 \mathrm{C} 66-823-\mathrm{SO}_{3} \mathrm{H}$ & 0.37 & 0.30 & 60.7 & 50.4 \\
\hline $\mathrm{Si} 50 \mathrm{C} 50-823-\mathrm{SO}_{3} \mathrm{H}$ & 0.25 & 0.37 & 50.5 & 42.1 \\
\hline $\mathrm{Si} 66 \mathrm{C} 33-823-\mathrm{SO}_{3} \mathrm{H}$ & 0.15 & 0.41 & 35.9 & 27.6 \\
\hline
\end{tabular}

\section{Hydrolytic hydrogenation of cellulose to sugar alcohols}

Another elegant strategy to valorise cellulose is inspired by a previous patent application by Jacobs et al. [13] on catalytic starch conversion. Such one-pot catalytic approach relies on a proton-catalyzed hydrolysis of the glycoside bonds, followed by fast metal-catalyzed hydrogenation of glucose into sugar alcohols such as sorbitol. Most recently, Geboers et al. [8] developed a novel catalytic system for the hydrolytic hydrogenation of cellulose, consisting of trace amounts of mineral acids and a bifunctional $\mathrm{Ru} / \mathrm{H}-\mathrm{USY}$ or $\mathrm{Ru} / \mathrm{H}-\mathrm{MOR}$ catalyst. The reported system exhibits exceptional activity and product selectivity, resulting in fast cellulose conversion with very high hexitol yields ( $>90 \%)$. Geboers et al. [9] also observed quantitative conversion of ball-milled cellulose with remarkable hexitol volume productivity for conversion of concentrated cellulose feeds over a combination of heteropolyacids $\left(\mathrm{H}_{3} \mathrm{PW}_{12} \mathrm{O}_{40}, \mathrm{H}_{4} \mathrm{SiW}_{12} \mathrm{O}_{40}\right)$ and $\mathrm{Ru}$ on carbon.

In an alternative approach by Van de Vyver et al. [7], Ni on carbon nanofiber catalysts (Ni/CNFs) are used for the catalytic hydrolytic hydrogenation of 
cellulose to sugar alcohols. While previous studies focus on cellulose cracking with expensive transition metals dispersed on porous supports, the concept of our catalyst design relies on the entanglement of threadlike carbon nanofibers (CNFs) around the water-insoluble cellulose matrix.

\subsection{Catalyst synthesis}

For the growth of CNFs, $20 \mathrm{wt} \% \mathrm{Ni} / \gamma-\mathrm{Al}_{2} \mathrm{O}_{3}$ was prepared by impregnating $\gamma$ $\mathrm{Al}_{2} \mathrm{O}_{3}$ (Condea Chemie; Puralox, $155 \mathrm{~m}^{2} / \mathrm{g}$ ) with an aqueous solution of $\mathrm{Ni}\left(\mathrm{NO}_{3}\right)_{2} \cdot 6 \mathrm{H}_{2} \mathrm{O}$ (Alfa Aesar), subsequent drying at $353 \mathrm{~K}$, calcination in static air at $873 \mathrm{~K}$ (heating rate $5 \mathrm{~K} / \mathrm{min}$ ) for $5 \mathrm{~h}$, and then reduction under $\mathrm{H}_{2}$ at $873 \mathrm{~K}$ for $1 \mathrm{~h}$. Samples of $0.5 \mathrm{~g}$ catalyst precursor were placed in a quartz reactor and the CNFs were grown at $873 \mathrm{~K}$ under $\mathrm{CH}_{4}$ flow $(80 \mathrm{ml} / \mathrm{min})$ for $3.5 \mathrm{~h}$. The resulting catalyst is denoted as $3.0 \% \mathrm{Ni} / \mathrm{CNF}$, where $3.0 \%$ represents the nominal weight value of $\mathrm{Ni}$ loaded on the CNFs.

\subsection{Catalyst characterization}

The CNFs grown over $\mathrm{Ni}$ supported on $\gamma-\mathrm{Al}_{2} \mathrm{O}_{3}$ were examined with $\mathrm{SEM}$ (Figure $8 \mathrm{a}, \mathrm{b}$ ). Furthermore, transmission electron microscope (TEM) images were recorded on a Philips CM30-FEG electron microscope, coupled to a postcolumn GIF200 system for electron energy loss spectroscopy (EELS) (Figure 8 d-f). TEM image 8e reveals elongated pear-shaped $\mathrm{Ni}$ nanoclusters with an aspect ratio of approximately 1.6 , on the tips of the CNFs.
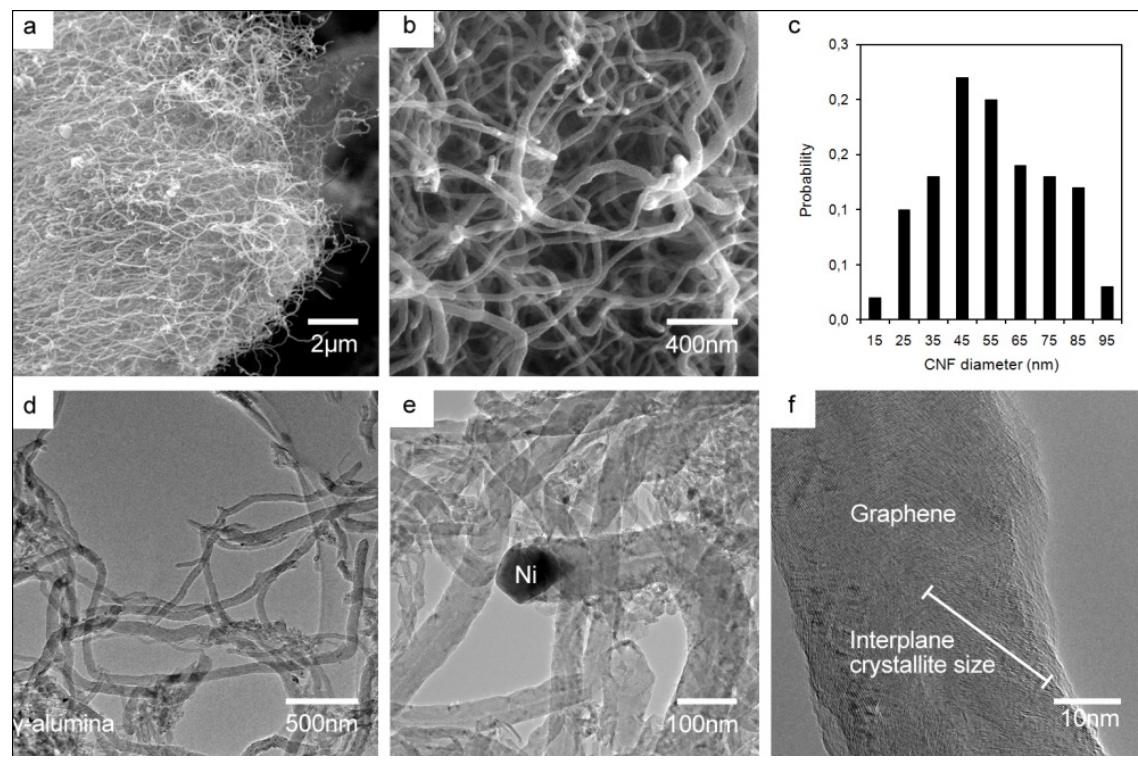

Figure 8: $\quad$ SEM images (a-b), CNF diameter distribution (c), and TEM images (d-f) of the $3.0 \% \mathrm{Ni} / \mathrm{CNF}$ catalyst sample. 
Figure 9 below displays the powder X-ray diffraction (PXRD) patterns of the as-prepared $3.0 \% \mathrm{Ni} / \mathrm{CNF}$ catalyst. The identified diffraction peaks are indicated with an arrow. Clearly, for Ni nanoclusters located at the end of the CNFs, the intensity of the more exposed $\mathrm{Ni}(111)$ surface exceeds the reflections of the other crystal planes. Indeed, progress in understanding the growth mechanism of CNFs has demonstrated the reaction-induced reshaping of Ni nanocrystals, unveiling a larger proportion of the thermodynamically more stable $\mathrm{Ni}(111)$ surfaces.

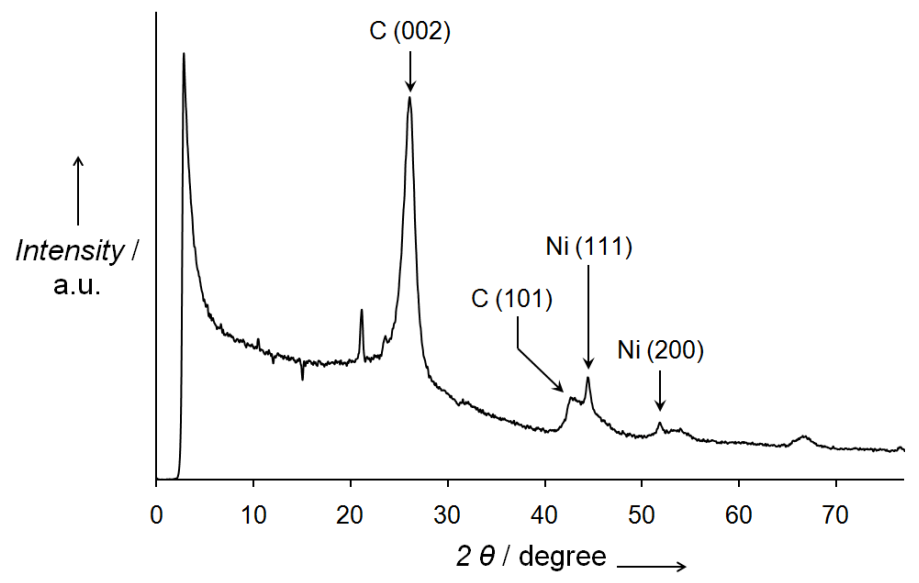

Figure 9: $\quad$ Powder X-ray diffraction pattern of the 3.0\% Ni/CNF catalyst.

Nitrogen physisorption data were recorded with a Micromeritics Tristar 3000 apparatus at $77 \mathrm{~K}$. Prior to physisorption measurements, the catalyst samples were evacuated at $473 \mathrm{~K}$ for $12 \mathrm{~h}$. The $\mathrm{N}_{2}$ adsorption isotherm of $3.0 \% \mathrm{Ni} / \mathrm{CNF}$ in Figure 10 can be classified as a type IV isotherm with a type B hysteresis loop. The agglomerated CNFs show a mesoporous structure, their BrunauerEmmet-Teller (BET) specific surface area is measured to be $76 \mathrm{~m}^{2} \mathrm{~g}^{-1}$ and their total pore volume $0.16 \mathrm{~cm}^{3} \mathrm{~g}^{-1}$.

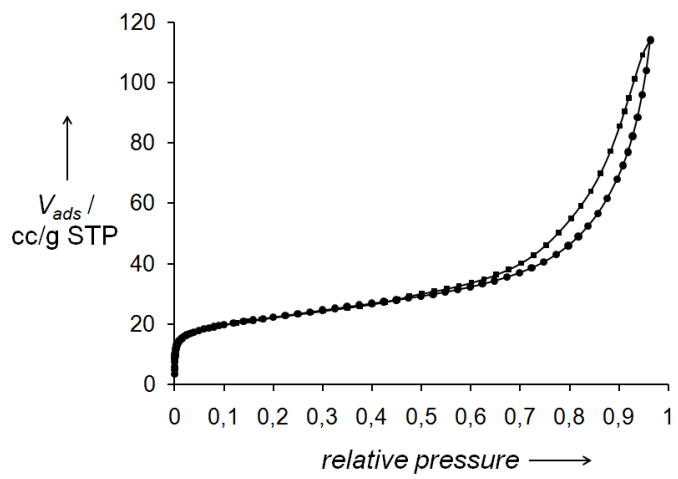

Figure 10: $\quad \mathrm{N}_{2}$ adsorption-desorption isotherm of $3.0 \% \mathrm{Ni} / \mathrm{CNF}$. 
Raman measurements were performed by putting the samples on top of a cleaned glass cover slip on an Olympus IX71 microscope. As excitation source a $633 \mathrm{~nm}$ wavelength laser was used. The laser light was reflected in the microscope on a $633 \mathrm{~nm}$ dichroic mirror towards a 100x 1.3 NA Olympus objective that focused the laser on the sample and collected the Raman signal. The Raman spectrum was recorded by using a Chromex Inc. Model 250 IS polychromator and a liquid $\mathrm{N}_{2}$ cooled $\mathrm{CCD}$ camera. Raman spectra of the samples are shown in Figure 11. All the spectra have two typical peaks centered around $1330 \mathrm{~cm}^{-1}$ (D-mode) and $1590 \mathrm{~cm}^{-1}$ (G-mode). The integral intensity ratio $I_{\mathrm{D}} / I_{\mathrm{G}}$ for the $3.0 \% \mathrm{Ni} / \mathrm{CNF}$ is 1.8 , which corresponds to an in-plane graphitic crystallite size $L_{\mathrm{a}}$ of $21.4 \mathrm{~nm}$.

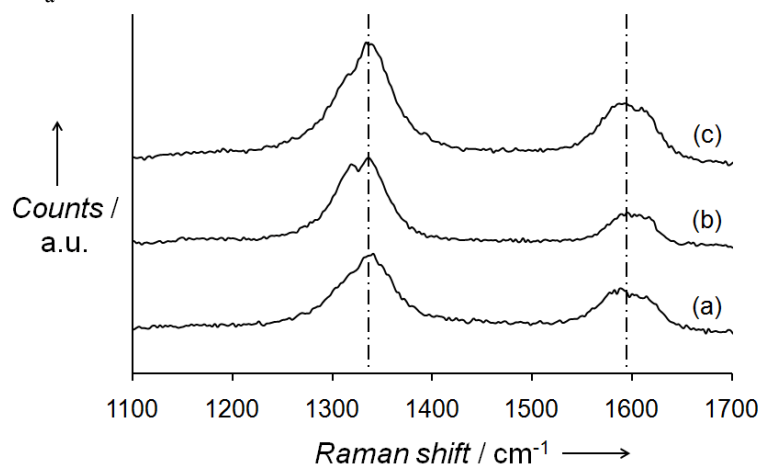

Figure 11: Raman characterization of the carbon nanofiber supported Ni:3.0\% $\mathrm{Ni} / \mathrm{CNF}(\mathrm{a}), 6.1 \% \mathrm{Ni} / \mathrm{CNF}$ (b) and 3.8\% Ni/CNF (c).

Nickel dispersions were determined using $\mathrm{CO}$ chemisorption (Figure 12). The $\mathrm{Ni} / \mathrm{CNF}$ sample was loaded into a tubular reactor and pretreated in a stream of 20 $\mathrm{mL} / \mathrm{min}$ of $\mathrm{H}_{2}$ at $573 \mathrm{~K}$ (heating rate $5 \mathrm{~K} / \mathrm{min}$ ) for $1 \mathrm{~h}$, and subsequently cooled to RT under a He flow of $20 \mathrm{~mL} / \mathrm{min}$. For the titration of the Ni surface, pulses of $5 \mu \mathrm{L}$ of $100 \% \mathrm{CO}$ were given with an interval of $2 \mathrm{~min}$. The $\mathrm{CO}$ concentration in the outlet stream was followed with a quadrupole mass spectrometer.

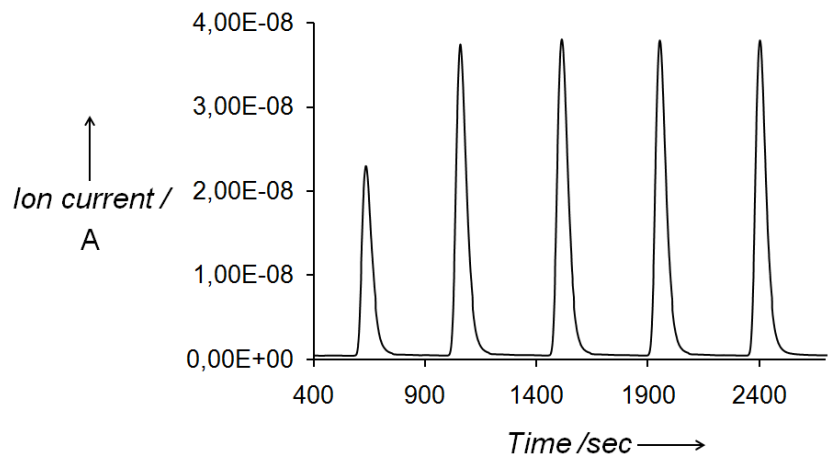

Figure 12: $\quad \mathrm{CO}$ chemisorption analysis of the $3.0 \% \mathrm{Ni} / \mathrm{CNF}$ catalyst. 
In the calculation of the dispersion, adsorption of $1 \mathrm{CO}$ molecule per accessible $\mathrm{Ni}$ atom was assumed. The $\mathrm{CO}$ chemisorption analysis of $3.0 \%$ $\mathrm{Ni} / \mathrm{CNF}$ yields a Ni dispersion of $0.17 \%$.

\subsection{Results and discussion}

With these well-characterized Ni/CNF catalysts in hand, Van de Vyver et al. [7] demonstrated the production of sugar alcohols in excellent yields up to $70 \%$ sugar alcohols (sorbitol 51\%, mannitol 6\%, erythritol 13\%) from ball-milled cellulose in a one-pot catalytic process. Sterically accessible Ni particles allow immediate hydrogenation of glucose, released after hydrolysis of cellulose. Despite the well-documented role of $\mathrm{Ni}$ as a hydrogenolysis catalyst, sorbitol appears to be surprisingly stable towards $\mathrm{C}-\mathrm{C}$ and $\mathrm{C}-\mathrm{O}$ bond breaking in the presence of the Ni/CNFs. In fact, the high hexitol selectivity of this catalyst is attributed to the structure-sensitive nature of the $\mathrm{Ni}$-catalyzed reactions.

\section{Conclusions and outlook}

Selective conversion of cellulosic biomass is relevant to the development of catalytic strategies for production of valuable chemicals and renewable fuel components. The implementation of advanced concepts from heterogeneous catalysis for cleavage of the $\beta$-1,4-glycosidic linkages between cellulose anhydroglucose units represents a significant challenge for catalysis and is of major interest to our and other research groups. Conceptually, it is proven that specific design of solid catalysts even allows efficient conversion of this most recalcitrant family of renewable substrates, thereby bridging the gap between cellulose chemistry and heterogeneous catalysis.

In this respect, bifunctional $\mathrm{Ni}$ on carbon nanofiber catalysts and sulfonated silica/carbon nanocomposites present interesting approaches for direct catalytic transformation of cellulose into sugar alcohols and glucose, respectively, with the ability to control the cellulose conversion and product distribution. However, since both of the discussed catalytic reactions are still in their infancy, future research will be aimed at further optimization of reaction conditions to attain higher selectivities and greater tolerance of the catalysts towards dissolution and leaching. Work along these lines is currently in progress.

\section{References}

[1] Van de Vyver, S., Geboers, J., Jacobs, P.A. \& Sels, B. F., Recent Advances in the Catalytic Conversion of Cellulose, ChemCatChem, 3(1), pp. 82-94, 2011.

[2] Lange, J.-P., Lignocellulose Conversion: An Introduction to Chemistry, Process and Economics (Chapter 2). Catalysis for Renewables: From Feedstock to Energy Production, eds. Centi, G. \& van Santer, R.A., WileyVCH, Weinheim, pp. 21-51, 2007. 
[3] Kamm, B., Production of Platform Chemicals and Synthesis Gas from Biomass, Angew. Chem. Int. Ed., 46(27), pp. 5056-5058, 2007.

[4] European Technology Platform for Sustainable Chemistry, Industrial Biotechnology Section, 2005, http://www.suschem.org

[5] Fan, L.T., Gharpuray, M.M. \& Lee, Y.-H., Cellulose Hydrolysis, Springer, Berlin, 1987.

[6] Van de Vyver, S., Peng, L., Geboers, J., Schepers, H., De Clippel, F., Gommes, C.J., Goderis, B., Jacobs P.A. \& Sels, B.F., Sulfonated silica/ carbon nanocomposites as novel catalysts for hydrolysis of cellulose to glucose, Green Chemistry, 12(9), pp. 1560-1563, 2010.

[7] Van de Vyver, S., Geboers, J., Dusselier, M., Schepers, H., Vosch, T., Zhang, L., Van Tendeloo, G., Jacobs, P.A. \& Sels, B.F., Selective Bifunctional Catalytic Conversion of Cellulose over Reshaped Ni Particles at the Tip of Carbon Nanofibers, ChemSusChem, 3(6), pp. 698-701, 2010.

[8] Geboers, J., Van de Vyver, S., Carpentier, K., de Blochouse, K., Jacobs, P. $\&$ Sels, B., Efficient Hydrolytic Hydrogenation of Cellulose in Presence of Ru-loaded Zeolites and Trace Amounts of Mineral Acid, Chem. Commun., accepted.

[9] Geboers, J., Van de Vyver, S., Carpentier, K., de Blochouse, K., Jacobs, P. $\&$ Sels, B., Efficient catalytic conversion of concentrated cellulose feeds to hexitols with heteropoly acids and $\mathrm{Ru}$ on carbon, Chem. Commun., 46, pp. 3577-3579, 2010.

[10] Zhao, H., Kwak, J. H., Wang, Y., Franz, J. A., White, J.M. \& Holladay, J.E., Effects of crystallinity on dilute acid hydrolysis of cellulose by cellulose ball-milling study, Energy Fuels, 20, pp. 807-811, 2006.

[11] Rinaldi, R. \& Schüth, F., Acid Hydrolysis of Cellulose as the Entry Point into Biorefinery Schemes, ChemSusChem, 2(12), pp. 1096-1107, 2009.

[12] Gommes, C.J. \& Goderis, B., CONEX, a program for angular calibration and averaging of two-dimensional powder scattering patterns, J. Appl. Crystallogr., 43, pp. 352-355, 2010.

[13] Jacobs, P. \& Hinnekens, H., Synfina SA, EP 0329923, 1989. 